\title{
DA IMPOSSIBILIDADE DE UMA EDUCAÇÃO TOLERANTE
}

\author{
Alexandre Lopes Campelo* \\ Rita de Cássia Pimenta de Araújo Campelo (Rita Pimenta)**
}

\begin{abstract}
RESUMO: O texto, neste artigo, trata de uma educação para tolerância, desenvolvida numa sociedade liberal. Entretanto, a assertiva a qual chegamos é a da impossibilidade desta tolerância, sob esse tipo de sociedade. Para tal constatação, realizamos uma investigação a respeito do conceito de tolerância talhado por Voltaire e Locke. Acompanhamos, ainda, a escuta deste conceito, em outras referências, agora contemporâneas. Assim, construímos dois quadros teóricos a partir de duas fontes seguras acerca do tema. Para a primeira delas, consideramos o livro Da Tolerância, de Michael Walzer (1999). Sobre a segunda, investigamos o livro Two Faces of Liberalism, de John Gray (2000). O primeiro livro finaliza o século XX e o segundo inicia o século XXI, dois momentos históricos importantes, o fim e o começo de séculos, para pensar um conceito cujas forças epistemológicas e ética podem ser observadas em tempos de diferenças brutais, pujantes nas sociedades, de modo particular na educação, na política e na filosofia.
\end{abstract}

PALAVRAS-CHAVE: Educar, Tolerância, Liberalismo, Pluralismo, Educação reflexiva, Democracia.

\section{THE IMPOSSIBILITY OF A TOLERANT EDUCATION}

\begin{abstract}
The text, in this article, deals with an education for tolerance, developed in a liberal society. However, the assertion we arrived at is the impossibility of this tolerance, under this type of society. To this end, we conducted an investigation regarding the concept of tolerance developed by Voltaire and Locke. We also follow the listening to this concept, in other references, now contemporary. Thus, we built two theoretical frameworks from two reliable sources on the topic. For the first of them, we considered the book Da Tolerância, by Michael Walzer (1999). For the second, we investigated the book Two Faces of Liberalism, by John Gray (2000). The first book ends the 20th century and the second begins the 21 st century, two important historical moments, the end and the beginning of centuries, to think of a concept whose epistemological and ethical forces can be observed in times of brutal, thriving differences in societies, particularly in education, politics and philosophy.
\end{abstract}

KEY WORDS: Educating, Tolerance, Liberalism, Pluralism, Reflective Education, Democracy.

\footnotetext{
* Mestre em Filosofia pela Universidade Federal do Rio de Janeiro - UFRJ. E-mail: campeloalexandre@yahoo.com.br Orcid: https://orcid.org/0000-0003-4806-5391

** Doutora em Educação Escolar pela Universidade Estadual Paulista - UNESP. Professora de Filosofia da Educação na Universidade Federal de Juiz de Fora - UFJF. E-mail: ritapimentar@yahoo.com.br

Orcid: https://orcid.org/0000-0002-3331-2276
} 


\section{INTRODUÇÃO}

Como entender a impossibilidade de uma educação tolerante, numa sociedade liberal? Eis a questão a ser respondida neste artigo. Para isso, retomaremos o conceito de tolerância, a partir de aspectos, principalmente filosóficos, visto que a filosofia é, sem dúvida, seu constructo primeiro, mas, claro, sem esquecermos que sua aplicação só é possível nas bases educacionais. Nosso esforço, ou mais um de nossos esforços é, também, pensar o referido conceito em uma perspectiva educativa e, ao mesmo tempo político-social. Neste sentido, visitamos os aspectos que moveram o conceito de tolerância no século XVI até o século atual, detendo-nos, de modo mais profundo, em dois bons momentos: o livro Da Tolerância e o livro Two Faces of Liberalism ${ }^{1}$. A apresentação e discussão dos principais aspectos dos dois textos, acima mencionados, dependerá, particularmente, de um esforço primeiro, a saber: começar a entender o conceito de tolerância a partir de seu principal formulador, Voltaire.

Voltaire, em seu Tratado sobre a Tolerância, no capítulo I - História resumida da morte de Jean Calas, fato que continua a ser visitado pelo filósofo ao longo do livro, relata a morte de um jovem, Jean Calas. Inicialmente, Voltaire nos põe em dúvida quanto às circunstâncias de sua morte. Por que esta dúvida, entre ser morto e suicidar-se? Depois do relato de Voltaire, descobre-se que o jovem se suicidou por não suportar a sua falta de absorção social, por não seguir nenhum credo religioso. Por outro lado, a população do lugar onde ele vivia, consumida pelos credos religiosos, torna sua morte em um assassinato, culpando seu pai e sua família, colocando-os como responsáveis pelo que eles chamaram de crime movido pelos seus fanatismos religiosos, culpando-os a tal ponto que sua família foi toda presa e condenada. A história é longa, valeria, certamente, à pena descrevê-la em sua íntegra, entretanto, este não é um de nossos objetivos, e a menção a tal fato tem a função de ilustrar o que se seguirá. Assim, recomendamos a leitura sobre o acontecimento. É possível dizer que tão intolerante como a história voltairiana, e aqui poderíamos tomar a liberdade de copiar seu estilo, são as diversas passagens, histórias e vivências de intolerância que conhecemos em nossos dias, as quais poderíamos relatar, recorrendo aos mais diversos registros histórico-documentais, ou mesmo, pragmaticamente, observando os bancos escolares.

É exatamente o conhecimento de tantas situações de recrudescimento, brutalidade e intolerância, pelas quais os seres humanos sofrem, que nos coloca não só na condição de observador, mas na condição de uma pessoa que as enxerga, analisando-as, tomando como perspectiva desta análise a necessidade de vinculá-las à problemática da tolerância. A realidade é sempre o berço da originalidade e, quando o que está em causa são vidas e condições que não passam pelo crivo da tolerância, o que resulta disso é a barbárie. A insistência da brutalidade, do ódio, do terror, do medo e da dor são

\footnotetext{
1 As citações feitas deste livro são traduções realizadas por mim. Provavelmente, há imperfeições, visto que não sou um tradutor juramentado, nem o traduzi com o objetivo de publicar tais traduções. Todavia, as citações são fruto do trabalho de estudo criterioso, realizado por mim, para discussão das ideias de John Gray, ao longo deste artigo.
} 
estampados, diuturnamente, em nossa realidade, inclusive, a escolar. O massacre das minorias, que não se conforma em ser um massacre moral, mas é físico também, é contado todos os dias. A repetição mercadológica, que vende em forma de manchete a dor, naturaliza a intolerância, a notícia, sem tempo para a reflexão, naturaliza a barbárie. A resistência ao silenciamento nos influencia e nos move neste trabalho. Centenas de casos de intolerância, suas localizações, suas personagens, têm suas vozes pseudoreveladas nos noticiários diários. No estudo que aqui estamos propondo, sua originalidade reside na presença, cremos, de defender asserções que justifiquem o valor histórico, político, educativo e ético da tolerância e seus regimes, como diria Walzer (1999), conceituais e formadores.

A vivência e conhecimento de casos de brutal intolerância, que ceifam as vidas, as esperanças, a compreensão de si e do outro servem como 'let motiv' que justifica, pessoalmente, o interesse pela pesquisa aqui proposta. O que mais vale numa situação de pesquisa são as contribuições que o tema transporta para a um tipo de sociedade que desejamos. Sem dúvida, a tolerância, seja na época de Locke, ou de Voltaire, agora na de Walzer ou Gray (2000) e, principalmente, na nossa, é pujantemente necessária, em diversos campos sociais.

Os expedientes que justificam a não tolerância exigem que a sociedade se eduque num cenário de cegueira, justificada, também, pelo argumento da busca de meios para honrar suas dívidas com a Igreja, com o Estado, do contrário, toda a prosperidade desabitará seu cotidiano. Em outros termos, a existência é dilacerada mais e mais, na medida em que nossos conselheiros sociais, Igreja, Estado, insistem que nossas vidas deles dependem, portanto, temos com eles dívidas eternas.

Há, aqui, um grande problema. Talvez, pudéssemos entendê-lo como um problema sóciopsicológico, sócio-histórico, que rege o funcionamento das instituições religiosas, políticas, sociais e educacionais. É difícil pontuar, factualmente, as razões específicas de casos particulares da ausência de tolerância, todavia, é esse desentendimento, ininteligência, de situações como os assassinatos de homossexuais, o aumento contínuo dos feminicídios (no Brasil e no Mundo), nas violências em âmbitos religiosos - que transformam seguidores em autômatos, guiados por uma fé incongruente com a realização humana, que deveria ser preenchida pelo significado do próprio ser. A barbárie contemporânea de um extermínio declarado dos homossexuais, das mulheres, cujos gritos já não podem ser silenciados, em um mundo que se vê a si mesmo, em tempo real, revela faces da miséria e do horror, reinantes de tragédias humanas. Estes e outros tantos dramas que ouvimos e vemos, por onde passamos, todos os dias, sem cessar, levam-nos a problematizar, debater, pesquisar e retomar a questão da tolerância, na urgência social que ela se coloca, propondo uma educação para a tolerância, que equaliza a sociedade liberal. 


\section{PRIMEIRA PARTE}

Propomos averiguar o conceito de tolerância, que chega até nós a partir de sua formação moderna, com John Locke, 1685 - 1686. É neste período em que o autor escreve sua Epistola sobre a Tolerância e Voltaire, em 1763, escreve seu Tratado da Tolerância, momento de extremo relativismo liberal e apelo durável à tolerância. Como homem de um outro tempo, compararei aquele tempo da tolerância moderna com o que parece incomparável, tomando aqui as ideias de Marcel Detienne (2004).

O conceito de tolerância, tal como o compreendemos neste trabalho, estabelece-se considerando que o princípio da tolerância é regido pela atividade política geral. Embora a teoria da tolerância tenha advindo, primeiramente, dos embates religiosos, visto que, os principais tratados sobre este conceito se deram no século XVII, "com as obras de Grócio, Bayle, Milton e Locke" (BOBBIO, 1998, p. 1246) ela, a teoria, difundiu-se em muitas outras formas de pensamento.

Em seu significado mais genérico, compreende-se por tolerância aquela que se estende às condições e aos comportamentos, que não deveriam ser tolerados por impedirem, ou impossibilitarem uma existência sem medo ou sofrimento. Marcuse (1970), por exemplo, afirmou que, embora a tolerância se justifique nos debates acadêmicos, sendo indispensável tanto na religião quanto na ciência, ela não pode ser comportada quando o que está em questão são a paz, a liberdade e a felicidade, pois, nesse caso, representaria o rechaçamento de todas as categorias de reformulação da realidade social.

Marcuse (1970, p. 87) argumenta, ainda, que a "tolerância afigura-se ser hoje o que foi em suas origens, no início do período moderno um objetivo partidário, práticas e ideias subversivas e libertadoras". Contudo, "o que se pratica e proclama hoje como tolerância serve em suas mais eficazes manifestações à causa da opressão”. Além disso, não podemos deixar de registrar que, para Marcuse (1970, p. 95), “a tolerância universal torna-se duvidosa apenas quando não mais prevalece seu fundamento lógico", e quando "a tolerância é administrada a indivíduos manipulados e doutrinados que repetem, como suas, as opiniões dos senhores para os quais a heteronomia se transformou em autonomia".

Wolf (1970, p. 12), por sua vez, diz-nos que a tolerância é a "virtude da moderna democracia pluralista surgida na América moderna”. Segundo ele, quando se trata da tolerância política, ela é um "estado de espírito e condição da sociedade que permite à democracia formular bem e concretizar o ideal de pluralismo". Wolf afirma que se quiséssemos compreender a tolerância como virtude política, deveríamos "estudá-la não através da investigação psicológica ou moral de preconceitos, mas através de uma análise da teoria e prática do pluralismo democrático”. Para Barrington Moore Jr. (1970, p. 69), “A tolerância implica a existência de um procedimento distinto para testar ideias, lembrando o julgamento justo no direito". Entretanto, ainda segundo este autor, "ninguém sustenta que de acordo com o processo de justo julgamento todos os acusados devam ser isentados". 
$\mathrm{Na}$ acepção religiosa, a tolerância significa renúncia em impedir alguns males, justificada pelo risco de que se forem impedidos à força se tornariam piores. O que a torna aceitável, como um mal necessário, dado ao fato de que se reprimida poderia trazer um ônus muito maior do que se aceitada. Isto evidência, para Norberto Bobbio (1998, p. 1246), que o conceito de "Tolerância constitui um grau preparatório do princípio de liberdade: a Tolerância institui, na verdade, um espaço de liceidade ou, pelo menos, de imunidade nas decisões individuais".

Uma outra acepção, que pode ser vista, é a que entendeu a tolerância como coexistência pacífica entre várias confissões religiosas, sendo hoje entendida, em sentido ainda mais geral, como coexistência pacífica de todas as possíveis atitudes religiosas. O critério para verificar se essa exigência está sendo realizada, as situações históricas e/ou políticas, é um só: a sua realização significa que o cidadão não sofre violência, inquirição jurídica ou policial, diminuição ou perda de direitos ou qualquer tipo de discriminação em virtude de suas convicções, positivas ou negativas, em matéria religiosa.

Alguns filósofos deixaram um legado muito importante acerca do princípio de tolerância. $\mathrm{O}$ historiador da filosofia Nicola Abbagnano (2000, p. 961 - 962) nos mostra a afirmativa inicial, ao historicizar o percurso do princípio de tolerância, quando descreve este princípio, colocando-o como a possibilidade de redenção, mesmo fora da fé cristã. Guilherme de Ockham é o responsável por essa assertiva, quando diz: "não é impossivel que Deus designe como digno da vida eterna todo aquele que viva segundo os ditames da justa razão e que só creia naquilo que sua razão natural indicar como digno de crença. E se Deus assim dispõe, poderia salvar-se mesmo aquele que na vida só teve como guia a justa razão" (OCKHAM, Apud ABBAGNANO, 2000, p. 961, grifo nosso).

Abbagnano (2000, p. 961), ao enfrentar a apresentação do conceito de tolerância, afirma que o princípio de tolerância aparece "como elemento indispensável da vida civilizada do Ocidente só depois da Reforma Protestante”. Mas ressalva que é provável que tenha sido afirmado, claramente, pela primeira vez, pelos socinianos, reformadores italianos que recusaram o dogma da Trindade. Alguns registros valem nosso destaque, por exemplo, em 1565, Giacomo Aconcio, em seu Stratabemata Satanae, via a intolerância religiosa como uma armadilha de Satanás. Em 1580, Montaigne defendia a liberdade de consciência. Por volta de 1593, Jean Bodin defendia, em Colloquium heptaplomeres, a necessidade da paz religiosa, a ser conquistada com um retorno à religião natural, que rejeitasse as controvérsias dogmáticas. Huig van Groot considerava fundamentais as crenças da religião natural, e não coercitivas as crenças da religião positiva, frequentemente ambíguas. Em 1644, Mílton escreve Areopagitica, a favor da liberdade de imprensa. Essas defesas do princípio de tolerância apelaram muito mais para argumentos políticos e religiosos do que filosóficos ou conceituais. Tal constatação nos leva a concluir, juntamente com Abbagnano, que nas empreitadas acima registradas, os argumentos foram, em sua maioria, religiosos, tendo muito mais valor para aqueles que compartilham as crenças religiosas para as quais fazem apelo.

Entretanto, o primeiro pensador a elaborar a defesa da tolerância em argumentos objetivos foi Spinoza, que apresentou em seu favor o argumento segundo o qual "a violência e a imposição não podem 
promover a fé; portanto, as leis que se propõem a esse fim são inúteis” (ABBAGNANO, 2000, p. 961 962). Acompanhando essa perspectiva, chegamos à Epistola sobre a Tolerância (1689). Locke, ao analisar os conceitos de Estado e de Igreja, demonstra que o princípio de tolerância é o ponto de encontro de suas respectivas tarefas e interesses. Se cabe ao Estado conservar e promover os bens civis, por exemplo, a vida, a liberdade, a posse dos bens externos, etc..., não lhe cabe o cuidado com as almas, pois seu único instrumento é a coação, e ninguém pode ser obrigado a salvar-se. No caso da Igreja, sendo uma sociedade livre de homens, unidos para servir a Deus, em público, do modo que julgarem mais aceito por Ele, com o fim de obter a redenção de suas almas', ela não pode vincular ninguém por meio da força. As sanções de sua competência são as exortações, as advertências e os conselhos. Todavia, fica claro na Epistola de Locke que o princípio de tolerância tem seus limites, visto que, para Locke, aquele que nega a existência de Deus não deve ser tolerado.

O princípio de tolerância, em sua forma usual, só passa a ser reconhecido com o Iluminismo, no século XVIII, e com o pensamento político liberal no século XIX. Conforme Abbagnano, a literatura posterior pouco acrescentou às justificações desse princípio, formuladas por Locke. Quanto ao Tratado sobre a Tolerância (1763), de Voltaire, este exercerá uma significativa influência histórica.

Não há dúvida de que após os esforços acima descritos, acerca do debate sobre a tolerância, ela, segundo Abbagnano, passou a fazer parte da consciência civil dos povos do Ocidente, contudo, sua realização nas instituições está sujeita a incompreensões, logo é incompleta. Além disso, precisamos considerar, também, que, quando a tolerância é discutida, muitas vezes o que mobiliza o debate é o desejo de "manter ou restabelecer privilégios em favor de alguma confissão religiosa específica, procurando-se, na melhor das hipóteses, fazer concessões formais ao princípio de Tolerância” (ABBAGNANO, 2000, p. 962).

Comumente, e às vezes na linguagem filosófica, alerta Abbagnano, a tolerância é compreendida, principalmente na sociedade contemporânea, como qualquer forma de liberdade ou pluralismo de valores, um meio "para manter o controle dos grupos sociais existentes" (ABBAGNANO, 2000, p. 962), configurando-se em impedimento à realização, acreditamos, de uma sociedade realmente democrática.

\section{SEGUNDA PARTE}

Valioso é o conselho de Michael Walzer (1999, p. 13) quando nos diz, em seu livro Da Tolerância, o seguinte: “comece sempre pelo lado negativo", ou seja, diga o que não pretende fazer. Ele assume a defesa da tolerância. Não trata da tolerância de sujeitos dissidentes ou excêntricos, em relação à sociedade civil ou ao Estado. Talvez, faça desta forma porque considera mais perigoso lidar com dissidentes quando estes estão agrupados. Não trata da tolerância política, pensando em grupos que constituem movimentos e partidos opostos. Neste sentido, faz um alerta necessário: é preciso permitir que grupos 
antidemocráticos joguem o jogo da política, pois isso permite, em um certo grau, medirmos nossa capacidade de tolerância.

O que guia Walzer (1999, p. 15), sobre a tolerância, é o fato de que, quando o que está em questão são as diferenças "culturais, religiosas, ou diferenças no modo de vida - quando os outros não são coparticipantes e não há jogo comum ou uma necessidade intrínseca para as diferenças que eles cultivam e praticam", a autonomia individual só pode ser conquistada quando se vive numa sociedade multicultural. Para essa conquista é preciso, alerta Walzer, suportar grupos provenientes deste multiculturalismo, isto significa ter certas atitudes ou estado de espírito. A primeira atitude foi provida nos séculos XVI e XVII - a tolerância religiosa, ou seja, "uma resignada aceitação da diferença para preservar a paz”; a segunda “atitude possível é passiva, descontraída, bondosamente indiferente à diferença: tem lugar para tudo no mundo"; a terceira é uma espécie de "estoicismo moral: um reconhecimento baseado no princípio de que os outros têm direitos, mesmo quando exercem tais direitos de modo antipático"; a última expressa uma abertura para com os outros; curiosidade, talvez respeito, uma disposição de ouvir e aprender. É o endosso entusiástico da diferença - "é um endosso estético, se a diferença for tomada como a representação cultural da grandeza e diversidade da criação divina ou do mundo atual” (WALZER, 1999, p. $16-17)$.

As pessoas que possuem as atitudes acima descritas são aquelas que aceitam homens e mulheres, cujas crenças não adotam, cujas práticas se recusam a imitar; os que têm tais práticas, agem assim, segundo Walzer, porque não levam "em conta sua posição no continuum da resignação, indiferença, aceitação estoica, curiosidade e entusiasmo, que se trata de pessoas que possuem a virtude da tolerância" (WALZER, 1999, p. 18). Pensar com Walzer nos move a pensar também por nós próprios, nosso corpus documental. Este, certamente, reflete o que há de mais peculiar sobre a tolerância.

A tolerância corresponde a certo estado da sociedade, isto é, ao modo como ela, ao longo do seu amadurecimento, conseguiu refletir suas prioridades. O pressuposto fundamental, a nosso ver, da tolerância, é o direito à vida (à existência, à integridade física e moral da pessoa e à não discriminação de todas as ordens). Esta é uma norma imperativa. Tal norma deve ser apreendida na escola.

Desde o seu surgimento, a tolerância, enquanto conceito, proporcionou um movimento do espírito que, ao mesmo tempo em que responde à necessidade elementar de proteção, no plano físico e moral, contra abusos de poder e contra as desigualdades das relações de força, abre um espaço para o debate contínuo dessa necessidade. Assim, o problema não está na inexistência de convenções acerca da tolerância, mas na necessidade da compreensão de que a tolerância está condicionada no espaço e no tempo, por múltiplos fatores de ordem histórica, política, econômica, social, cultural e educacional. Logo, seu real conteúdo está definido de modo diverso e suas modalidades de realização variarão. Michael Walzer (1999) demonstra isto no seu livro Da Tolerância, como já mostramos.

Em vista de tal diversidade, reflexo da própria diversidade das sociedades e das concepções do homem, precisamos reconhecer que a tolerância pode ser concedida e garantida pelos órgãos do Estado, 
para promover o estabelecimento de condições humanas de vida, assim como o desenvolvimento multidimensional da pessoa, talvez, aqui, pudéssemos comparar tolerância com Direitos Humanos.

Não é difícil percebermos a complexidade desse debate, cuja possibilidade de sua constituição se dá, acreditamos, apenas em ambientes democráticos, que favorecem um alargamento progressivo da tolerância. Quando analisamos as discussões produzidas sobre a tolerância, verificamos que os direitos civis, políticos, econômicos, sociais, culturais e educacionais constituem um conjunto de valores essenciais para a manutenção da dignidade, da liberdade e do bem-estar dos seres humanos. Essa noção é ampliada na medida que há a defesa de que tanto os direitos políticos, quanto os sociais são elementos de uma sociedade na qual a liberdade política e a justiça social devem representar valores predominantes. A sociedade democrática deve, portanto, unir os anseios políticos e sociais de seu povo. Esse procedimento permitirá a proteção do fraco, do vulnerável, considerando as exigências de solidariedade e respeito, ampliando a possibilidade do profundo desenvolvimento humano.

Entretanto, enquanto a miséria, em todos os sentidos que essa palavra comporta, reinar, a tolerância se constituirá em uma ilusão. O desenvolvimento humano é, portanto, condição para uma realização cada vez mais completa da tolerância. O direito ao desenvolvimento humano deve ser afirmado numa relação dialética entre o Estado e os indivíduos, o que garantiria uma percepção tolerante da união homoafetiva, de uma educação anti-feminicida, da livre-escolha religiosa, dos cultos para as mais diversas divindades. Portanto, o debate sobre a tolerância está permeado pela complexidade da constituição de um modo de vida democrático. É no reconhecimento das diversas experiências vividas, que encontramos as expressões da necessidade de criar homens livres, que sejam capazes de entender o sentido de tolerância, dentro da sua educação primeira, ou seja, na infância.

Assim, defendemos que a efetiva abordagem da tolerância, tal como foi aqui caracterizada, só se realiza na democracia. A democracia surge, portanto, como o fundamento básico para a realização da tolerância. A democracia, encarada como um modo de vida, isto é, como um espaço de vida compartilhada em constante debate, no qual sejamos capazes de identificar nossas diferenças e necessidades, permitenos a exigência da justiça social.

Neste contexto, entendemos que a questão mobilizadora ganha legitimidade, visto que, aqui, defendemos que a cidadania, diante do que expusemos acima, não é um mero conceito formal, sem uma efetiva preocupação por sua formação. Ao contrário, a cidadania, como a democracia têm por base a constituição da autonomia que, por sua vez, parte do princípio de que deve ser apreendida como exercício virtuoso da ação tolerante. Sem a práxis não há autonomia para a constituição dessa ação tolerante. Sem dúvida, o lugar de aprendizagem tem muito a contribuir com tal ação.

Um novo sentido da liberdade se abre, porque não nascemos sabendo ser livres, temos que aprender a viver como pessoas livres. Defendemos que lugares privilegiados, para que essa prática acerca da liberdade aconteça, podem ser as instituições e/ou ambientes de formação humana, por exemplo, a escola. Neste ponto, na construção da subjetividade virtuosa, que aprende criticamente a ser livre, é 
imprescindível repensar o sentido da tolerância a partir da alteridade, do outro como referência éticopolítica do bem e da justiça. A democracia pode servir a interesses egoístas, todavia, na compreensão que a tomamos neste texto, ela se realiza quando favorece "uma forma de vida associada, de experiência conjunta e mutuamente comunicada" (DEWEY, 1959, p. 93). Muito provavelmente, a busca por esse modo de vida é um dos veios que possam assegurar o que alguns já chamaram de tolerância verdadeira, e, ambas, democracia e tolerância, não sobrevivem ao liberalismo e, mais uma vez, conscientizamo-nos de sua impossibilidade.

\section{TERCEIRA PARTE}

Em Two Faces of Liberalism, John Gray (2000) nos revela que o regime liberal contemporâneo é posterior ao projeto da tolerância, que começou na Europa do século XIX. Supomos que, certamente, John Gray (2000) se refere ao trabalho de John Locke. Quando Gray (2000, p. 01) nos fala que “nós herdamos a tarefa de remodelar a tolerância liberal, assim que assumimos a atividade do 'modus vivendi' num mundo mais plural", pensamos junto com ele que, realmente, considerar o mundo com suas diversidades é um desafio, que nos faz construir um novo modo de tolerância liberal. Talvez fosse deste modo que começavam a pensar os intelectuais brasileiros, e, talvez, esteja, aqui, mais uma formação de nossa impossibilidade de educar para a tolerância.

Por enquanto, sigamos Gray, pontuando seus entendimentos, que nos alertam para o fato de que a tolerância liberal nos deixou de herança personificações de duas filosofias incompatíveis: a primeira, a tolerância como um ideal do consenso racional - "um dos melhores caminhos da vida" (Gray, 2000, p. 01). Nesta alternativa, as consequências foram a migração das massas, as novas tecnologias da comunicação e a continuada experimentação cultural. A outra filosofia, é a que admite que hoje, quase todas as sociedades possuem vários caminhos de vida. Tal ideia nasceu em sociedades divididas, a respeito da reivindicação de um simples caminho de vida.

Assim, Gray (2000, p. 02) observa que na antiga Alexandria, nos budistas indianos, entre os romanos, os mouros e os otomanos, "diferentes crenças coexistiram em paz por longos períodos". A constatação leva Gray a conjecturar que a primeira face do liberalismo é uma prescrição para um regime universal; a segunda, é um projeto de coexistência que pode ser buscado em muitos regimes.

O raciocínio de Gray (2000) segue vislumbrando algumas grandes teorias, por exemplo, diz-nos que John Locke e Immanuel Kant ilustram o projeto liberal de um regime universal; enquanto Thomas Hobbes e David Hume expressam o liberalismo de tranquila coexistência. Em tempos mais recentes, acentua que John Rawls e F. A. Hayek têm defendido a primeira filosofia liberal, enquanto Isaiah Berlin e Michel Oakeshott são exemplos da segunda. Por conta de Locke, a tolerância liberal foi considerada ceticamente em relação à verdade da religião ou da moralidade. Pressupõe que a verdade foi fundada e 
imposta numa moral sobre como promover um governo, numa época em que a tolerância a respeito das coisas se dava na medida em que eram julgadas para serem más ou falsas.

Quanto à perspectiva de Locke, Gray (2000) aponta para um estudo sobre a penetrante dependência do pensamento político de Locke à religião, feito por John Dunn $(1969)^{2}$ Segundo Gray (2000), Locke entendeu tolerância como um caminho para uma exata religião.

Quanto a Hobbes, nada sugere, até onde pudemos averiguar, um entendimento de tolerância como um caminho para a verdadeira crença. Para ele, tolerância era uma estratégia de paz. Indiferente à crença, a única preocupação do governo era com a prática. Nisto, o hobesianismo via o fim da tolerância como um não consenso. Em outras palavras, era coexistência [Michael Oakeshott escreve sobre isto em Hobbes ou Civil Association - 1975.].

Sobre os pensadores liberais, Gray (2000, p. 03) argumenta que eles nunca estiveram completamente irmanados com o pensamento que assegura a fé, como princípio para se ter uma boa vida, todavia, eles sempre estiveram "conscientes da força e paixão para ver razão em qualquer coisa a mais, que um frágil poder do prazer humano". Era esta manifestação da imperfeição da razão humana, que embasava o ideal de tolerância como um significado para o consenso.

Nos passos de Gray, pudemos entender que regimes liberais são, muitas vezes, vistos como soluções para o moderno problema do pluralismo. Além disso, precisamos atentar fortemente quando Gray (2000, p. 04) nos alerta o seguinte: “o que é novo no mundo moderno não é aceitação da diversidade de estilos de vida. É a hostilidade para hierarquias”, este alerta, certamente, nos garantirá uma próxima investigação. Fora isto, não é possível deixar de pinçar esta reflexão, talvez bem conhecida, mas poucas vezes comentada, em que ele percebe, que a cultura de onde a filosofia moral europeia emerge, contém muitas formas da vida ética.

Gray (2000) escrutina isto ao expor que o politeísmo grego expressa a crença de que as origens dos valores são irredutivelmente plurais. Neste sentido, debate como funcionava a vida ética na Antiguidade, a fim de ir aos fundamentos da Teoria Ética Europeia e acaba percebendo que a influência do mundo antigo na Teoria Ética Europeia não foi tão densa como se possa pensar, mas admite ter sido significativa. Penso isso, a partir da seguinte citação: "Para os fundadores da Teoria Ética Europeia, bem como para os Cristãos, que chegaram após eles, conflitos de valores eram, signos da imperfeição, não uma parte normal da ética da vida" (GRAY, 2000, p. 04).

Tanto para a Filosofia Moral, como para o Pensamento Político, é preciso lutar para exorcizar conflitos da vida ética. Por isso, pensadores liberais consideram que é melhor começar a entender os conflitos, seja da cidade, bem como da alma, como circunstâncias inevitáveis. Os conflitos são o Modus vivendi.

\footnotetext{
2 The pervasive dependency of Locke's political thought on a particular version of the Christian religion has been shown in John Dunn's classic study The Political Thought of John Locke: An Historical Account of the Argument of the 'Two Treatises of Government', Cambrige University Press, 1969 (Apud, GRAY, 2000, p. 140).
} 
Na esteira de Gray (2000), o Modus vivendi é o ideal de cada um. Este é personificado na velha corrente de pensamento liberal acerca da tolerância e aplicado em nossas próprias circunstâncias novas.

O Modus vivendi expressa a crença, que há muitas formas de vida, em que humanos podem desenvolver-se. Entre estas há algumas, cujo trabalho não pode ser comparado. Os caminhos de vida são concorrentes, não há um único deles, que seja melhor. Pessoas que pertencem à diferentes caminhos de vida, não precisam ter divergências. Elas podem simplesmente ser diferentes (GRAY, 2000, p. 05).

Ressalto que vale pensar bem sobre uma outra premissa: "para o ideal predominante da tolerância liberal, a melhor vida pode ser inatingível, mas é o melhor para todos” (GRAY, 2000, p. 05). Deste ponto de vista do modus vivendi, nenhum tipo de vida pode ser bom para todos. Nossos ideais de tolerância herdados aceitam como regra o fato de que há muitos caminhos de vida. Se adotarmos o modus vivendi como nosso ideal, o acolheremos bem.

É importante registrar, ainda, a partir do modus vivendi, que "nós não precisamos de valores comuns para vivermos juntos e em paz. Nós precisamos de instituições comuns, em que muitas formas de vida possam coexistir" (GRAY, 2000, p. 06). Esta reflexão, certamente, no contexto atual é bem valiosa, pois, ao que parece, este entendimento passa bem longe dos diversos entendimentos políticos presentes na sociedade brasileira.

A vida boa (justa) pode não ter um único caminho, tanto no plano das comunidades ou tradições, como também no plano dos regimes políticos. O "Modus vivendi” é tolerância liberal adaptada ao fato histórico do pluralismo" (GRAY, 2000, p. 06). Logo, há maneiras de operar que não podem ser comparadas. É preciso pensar mais profundamente sobre isto, principalmente, quando nos referimos ao ambiente escolar e às universidades, mas, também, quando nos referimos às mais diferentes atuações profissionais, que lidam com a saúde, com a justiça, com a moradia e com a assistência social.

Gray nos faz refletir se o pluralismo de valores está próximo, ou pode ser confundido com ceticismo, subjetivismo ou relativismo, e vai nos incitando com suas assertivas. Estas passam por diversos pontos, tais como: “afirmar que o bom é plural, é permitir abrigar conflitos, por onde há não uma única solução que seja certa. E não que aquela possa ser solução errada de cada conflito. Senão, há muitas” (GRAY, 2000, p. 06). Parece-me que tal assertiva se refere a um pressuposto lógico, que pode ser melhor explicado quando Gray (2000) mostra que a contradição não é aceitável pela Lógica clássica. Parece-me que tal discussão lógica é posta por Gray para que ele chegue à discussão acerca da justiça, considerando vários aspectos que implicam a justiça e a injustiça. Tomando esta via, Gray (2000, p.08) afirma que “soluções incompatíveis de cada conflito podem razoavelmente equilibrar-se”. E mais, “(...) Esses conflitos entre valores universais podem se acomodar em caminhos incompatíveis e é a única razão por que pessoas tomam caminhos de vida diferentes" (GRAY, 2000, p. 08).

A continuidade da discussão sobre a tolerância liberal traz a percepção que "a pegada entre as exigências de diferentes caminhos de vida é uma origem comum do conflito moral” (GRAY, 2000, p. 08) 
e é um sinal de que humanos podem viver bem em diferentes caminhos. Em outras palavras: "há humanos universalmente bons e maus. Algumas virtudes são necessárias para alguns tipos de prosperidade humana. Sem coragem e prudência a vida não pode seguir bem. Sem simpatia para o sofrimento e alegria de outros, o artefato da justiça não pode manter-se" (GRAY, 2000, p. 08).

Valores universais nos permitem avaliar caminhos de vidas particulares, mas eles não acumulam moralidades universais. Lucidamente Gray (2000) observa que, o que nos permite pensar em apoiar um estado forte, como um baluarte contra a anarquia, pode agravar o abuso de poder. "Sábia política pode temperar estes conflitos. Não pode esperar para superá-los” (GRAY, 2000, p. 09).

Uma questão importante, ventilada por Gray, é a de que "a ideia de uma vida humana, que seja sem conflitos de valores, encalhada nas contradições das necessidades humanas" (GRAY, 2000, p. 09), pode vir a ser a corrosão de sistemas políticos. Por outro lado, Gray ressalva: “cada vida personifica virtudes que não coexistem facilmente; e elas podem expressar crenças que são contraditórias” (GRAY, 2000, p. 10).

Acabamos percebendo que as melhores vidas humanas são muito diferentes umas das outras, "e muitas vezes incompatíveis (...). Isto não é uma lógica da verdade. É um fato sobre a natureza humana" (GRAY, 2000, p. 10). Insiste Gray (2000, p. 10) que "o pluralismo de valores significa mais que simplesmente tragédia. Significa que há muitos tipos de vida em que humanos podem desenvolver-se." $\mathrm{E}$, deste modo, pluralizar-se sem as amarras ditatoriais estabelecidas por regimes, que não toleram os diferentes.

Veremos, no desenvolvimento deste raciocínio, que o pluralismo de valores não interage continuamente, suas distinções não são fáceis de serem dadas por completo. Este pluralismo já se realizava destas maneiras antes das sociedades modernas e assume variadas formas e atuações, que não estão dadas a priori. Enfim, os critérios de medida do pluralismo de valores podem ser extremamente soltos, imprecisos. Todavia, se sabe que "em quase toda sociedade contemporânea a coexistência de muitos caminhos de vida é um fato aceito" (GRAY, 2000, p. 11).

Sobre a reflexão liberal contemporânea, quando ela se refere ao pluralismo, ela acredita nas crenças e ideais ético-pessoais; o "que não é o tipo de pluralismo que muitas filosofias políticas se preocupam” (GRAY, 2000, p. 12). Gray (2000) precisou admitir que o pluralismo, nos moldes de sua existência contemporânea, não foi previsto pela reflexão liberal. O que se percebe é que mesmo agora não tem sido realmente compreendido.

Os conflitos de valores, que formam a agenda do pensamento político, não chegam da divergência de ideais dos indivíduos, mas das reivindicações opositoras dos caminhos de vida. Aponta Gray de outra forma: a "ortodoxia liberal recente passa sobre estes conflitos, porque toma como garantia que um único caminho de vida é dominante na sociedade" (GRAY, 2000, p. 12). 
É importante dizer que em sociedades modernas anteriores, o pluralismo de valores tinha relevância particular, mesmo por escolha, por acaso ou fato e muitos caminhos de vida podiam coexistir. Hoje, entende nosso autor, que o pensamento liberal precisa remodelar sua interpretação da tolerância.

Além disso, é possível perceber que nunca houve uma síntese dos valores da tradição ocidental e nem poderia ter havido. $\mathrm{O}$ "liberalismo precisa repensar-se para adequar um contexto em que diferentes ideais de vida coexistam nas mesmas sociedades - e frequentemente nos mesmos indivíduos" (GRAY, 2000, p. 13). O pensamento liberal convencional manipula para o mal entendimento deste fato, isto é, existir a coexistência de diferentes caminhos de vida, porque tomam como garantia um consenso sobre valores liberais. Todavia, tal pensamento liberal sabe que há pouco consenso a respeito de seus valores.

Gray (2000, p. 13) argumenta ainda que, “para todos os tipos de pessoas, 'tradicionais', 'liberais' e 'pós-modernos', ética de vida é inescapavelmente híbrida". Também observa que onde existisse a hegemonia do discurso liberal, ele era tornado frequentemente superficial. Sem bases seguras que o sustentassem.

A figura da nação mais falada do planeta, os USA, surge nesse debate a respeito da Tolerância Liberal, com a seguinte assertiva, a saber: "os Estados Unidos não são hegemonicamente liberais, mas moralmente pluralistas" (GRAY, 2000, p. 14). O pluralismo, como "Teoria da Justiça”, manifestado no liberalismo político de John Rawls e seus seguidores, indica um tipo de justiça aceitável por diferentes pessoas que têm concepções de bondade diferentes.

Depois de discutir um pouco a respeito da "Teoria da Justiça", uma das mais enfáticas assertivas postas por Gray (2000, p. 15) é aquela que defende que a "sociedade contemporânea ainda não contém um consenso sobre a justiça, que seja profundo ou largo suficiente para uma grande 'Teoria da Justiça' ". $\mathrm{Na}$ discussão posta pelo autor apareceram outros teóricos, tais como: Ronald Dworkin, F. A. Hayek e Robert Nozick. Após esta precisa discussão sobre a “Teoria da Justiça”, Gray (2000, p. 16) admite que, hoje em dia, "a maioria dos pensadores liberais afirma que a justiça é a virtude suprema das instituições sociais". O que o leva à formulação de um problema: Qual o empreendimento objetivado por pensadores contemporâneos liberais? Tentar construir uma Teoria da Justiça.

Quando pensadores liberais recentes reivindicam que o liberalismo é uma doutrina política estrita, eles mostram que não depende de alguma noção compreensiva de virtude. Eles não se cansam de nos revelar que as demandas da justiça devem receber prioridade sobre alguns ideais de virtude. Eles rejeitam o fato que diferentes pontos de vista de virtude suportam diferentes pontos de vista de justiça (GRAY, 2000, p. 16).

As muitas possibilidades de pensar a Teoria da Justiça passam por Rawls, Hayek, Dworkin, Nozick, e, ao escrutiná-los, Gray (2000) vislumbra caminhos de vida extremamente severos, que não partem de concepções primárias da virtude humana, mas que também pouco podem se sobrepor a um compromisso de permitir o desenvolvimento único de uma concepção geral de justiça. 
O que lhe revela mais uma necessária pergunta: quando caminhos de vida diferem enormemente de seus pontos de vista da virtude, eles não suportarão diferentes pontos de vista de justiça? Segundo Gray (2000), os legalistas liberais objetivam circunscrever um conflito entre a vida virtuosa por encantadoras ideias de justiça e direitos. Para isso, reivindicam uma linhagem que remonta a Kant, que procura desenvolver uma filosofia política baseada somente no direito. (...) "O direito nunca pode ser prioridade da virtude. Sem o conteúdo que pode ser dado somente por uma concepção de virtude, o direito é vazio" (GRAY, 2000, p. 19).

Quanto aos regimes políticos, Gray nos revela uma distinção entre regimes liberais e não liberais. É preciso dizer que essa distinção não é categórica. Reconhecemos regimes liberais não por terem propriedades essenciais, mas por suas semelhanças familiares. O que nos remonta a um retorno ao pluralismo de valores, onde podemos perceber que ele entende o liberalismo como um ideal político.

Algo que nos chama a atenção, também, é a admissão de que nós humanos prosperamos em diferentes formas de vida. Nenhum humano pode razoavelmente reivindicar para prosperar o florescimento do que é unicamente humano. Se há algo que distinga a espécie humana, é que ela pode prosperar em diversos caminhos.

Há, ao longo da continuidade de suas explicações, um retorno a questões que surgiram no início de seu trabalho, todavia, é necessário registrar que, no seu retorno a Hobbes, Gray afirma que este é o progenitor de uma tradição liberal, que pensou o modus vivendi como uma ideia central. Vale à pena também registrar, ainda sobre os regimes liberais, que eles são para um estado de propriedades essenciais, bem como teorias liberais e pensadores que não se assemelham, mas têm ideias comuns. Gray (2000) assegura ser um erro básico procurar pela essência de algo, em um universo heterogêneo e descontínuo como o da tradição liberal. Liberalismo, para ele, não é o tipo de coisa que tenha uma essência.

Neste momento, muitas são as referências tomadas para análise de Gray (2000), a saber: Hayek, Locke, Adam Smith, David Hume, Hobbes, Karl Marx, Micahel Oakeshott, Alexis de Tocqueville, JeanJacques Rousseau, De Maistre, Immanuel Kant, Frederich Nietzsche, James Fizjames Stephen, John Stuart Mill, Michel de Montaigne, etc. O uso de todos estes e outros pensadores nos fez, assim como fez a Gray, perguntarmo-nos: como fizemos com os regimes liberais e não liberais? Gray (2000, p. 27) responde: "reconhecemos estes pensadores como pertencendo a uma tradição de pensamento liberal não em virtude da exibição de características estabelecidas, mas por sua semelhança familiar".

É importante, ainda, voltarmos nossa atenção para a citação que segue: No entanto, como vou mostrar, a tentativa de Berlim para aterrar o liberalismo em uma teoria ética, o pluralismo de valores, decompõe em muito da mesma maneira como fez a tentativa de Mill para a construção de um utilitarismo liberal (GRAY, 2000, p. 32).

Tal observação reflete o porquê do modus vivendi rejeitar a afirmação dos valores liberais a autoridade universal. Ele é obrigado a estar em desacordo com a filosofia prevalecente de tolerância liberal. No entanto, o modus vivendi ainda pode pretender ser uma renovação do projeto liberal. Para Gray, 
continua a busca da paz que a tolerância liberal começou. Gray, felizmente, espalha uma centena de rastros aos nossos pensamentos e reflexões, e deixa a dúvida mais presente do que antes a respeito da impossibilidade de uma educação tolerante numa sociedade liberal.

\section{CONSIDERAÇÕES FINAIS}

Diante à exposição de motivos, dissecados por nós, acerca das duas faces do liberalismo e por saber de sua ascensão, bem como sua solidificação nas estruturas contemporâneas do pensamento, entre elas o pensamento filosófico educativo, resta-nos um olhar jamais conformado, mas compreensivo que, ao tempo que compreende e lamenta as dificuldades e empecilhos para a constituição de uma educação tolerante, vê sua impossibilidade em nossa sociedade liberal. Vale, claro, o registro de que uma educação tolerante só se consubstanciaria numa vida realmente democrática, que surgiria a partir de uma ampla defesa e ensino do pensar reflexivo, premissa defendida na segunda parte deste artigo.

Este, o pensamento reflexivo, como tem nos mostrado uma pesquisadora brasileira, através de seus estudos da obra do filósofo John Dewey, envolve a formação de juízos e esta formação só ocorre em uma sociedade democrática. Sendo assim, Rita Pimenta (2009) nos recomenda que a sociedade democrática, tal como é descrita por John Dewey, seria o único ambiente em que se pode realizar plenamente uma lógica como investigação, ou seja, capaz de formar juízos reflexivos, e, consequentemente, uma educação reflexiva, que, a nosso ver, pode recorrer ao princípio da tolerância.

Este pensamento, recomendado por Pimenta (2009), já nos garante novos estudos, e consequentemente, novos textos, onde poríamos à prova a possibilidade da educação tolerante frente ao pensamento reflexivo democrático, numa sociedade como a brasileira, que se fez liberal, mas, ainda, profundamente intolerante. 


\section{REFERÊNCIAS}

ABBAGNANO, Nicola. Dicionário de filosofia. Tradução da $1^{a}$ edição brasileira coordenada e revista por Alfredo Bosi; revisão da tradução e tradução dos novos textos Ivone Castilho Benedetti - $4^{a}$ edição - São Paulo: Martins Fontes, 2000.

BOBBIO, Norberto; MATTEUCCI, Nicola; PASQUINO, Gianfranco. Dicionário de Política. Tradução Carmem C., Varriale et ai.; Coord. Trad. João Ferreira; rev. Geral João Ferreira Luis Guerreiro Pinto Cacais. - Brasília: Editora Universidade de Brasília, $1^{\text {a }}$ edição, 1998.

DEWEY, John. Como pensamos: como se relaciona o pensamento reflexivo com o processo educativo: uma reexposição. Tradução Haydée de Camargo Campos. 3. edição. São Paulo: Nacional, 1959a.

DETIENNE, Marcel. Comparar o incomparável. Tradução: Ivo Stoniolo - Aparecida, São Paulo: Ideias \& Letras, 2004.

GRAY, John. Two Faces of Liberalism. Published in the United States by The New Press, New York, 2000.

LOCKE, John. Ensaios Políticos. Tradução: Eunice Ostrensky - São Paulo: Martins Fontes, 2007.

MARCUSE, Herbert. Tolerância Repressiva. In.: Crítica da Tolerância Pura. Tradução: Ruy Jungmann - Rio de Janeiro: Zahar Editores, 1970.

MOORE JR, Barrington. A Tolerância e o Ponto de Vista Científico. In.: Crítica da Tolerância Pura. Tradução: Ruy Jungmann - Rio de Janeiro: Zahar Editores, 1970.

PIMENTA, Rita. Lógica, Investigação e Democracia no Discurso Educacional de John Dewey. Tese de Doutorado - Programa de Pós-Graduação em Educação Escolar da Faculdade de Ciências e Letras da UNESP - Araraquara - São Paulo, 2009.

TEIXEIRA, Anísio. Apresentação. In: DEWEY, John. Democracia e educação: introdução à filosofia da educação. Tradução Godofredo Rangel e Anísio Teixeira. 3. edição. São Paulo: Nacional, 1959.

WALZER, Michael. Da Tolerância. Tradução: Almiro Pisetta - São Paulo: Martins Fontes, 1999.

WOLFF, Robert Paul. Além da Tolerância. In.: Crítica da Tolerância Pura. Tradução: Ruy Jungmann - Rio de Janeiro: Zahar Editores, 1970.

VOLTAIRE. Tratado sobre a tolerância. Tradução: Paulo Neves - São Paulo: Folha de São Paulo, 2015. 